\title{
Possible Link between Metabolic Syndrome and Chronic Kidney Disease in the Development of Cardiovascular Disease
}

\author{
Kosaku Nitta \\ Department of Medicine, Kidney Center, Tokyo Women's Medical University, 8-1 Kawada-cho, Shinjuku-ku, Tokyo 162-8666, Japan \\ Correspondence should be addressed to Kosaku Nitta, nitta@kc.twmu.ac.jp \\ Received 6 August 2010; Accepted 6 September 2010 \\ Academic Editor: Ken-ichi Aihara \\ Copyright () 2011 Kosaku Nitta. This is an open access article distributed under the Creative Commons Attribution License, which \\ permits unrestricted use, distribution, and reproduction in any medium, provided the original work is properly cited. \\ Metabolic syndrome (MetS) is a clinical syndrome that consists of visceral obesity, dyslipidemia, hypertension, and impaired \\ insulin sensitivity. Although individual components of MetS have been implicated in the development of chronic kidney \\ disease (CKD), few studies have examined the effect of combinations of the components of MetS on the development of \\ $\mathrm{CKD}$ and cardiovascular disease (CVD). The prevalence of MetS is increasing worldwide in both developing and developed \\ countries, and early detection and treatment of MetS would be a cost-effective strategy for preventing the development of CKD. \\ Visceral obesity and insulin resistance are two important features of MetS that may be associated with renal damage. Lifestyle \\ modifications, including caloric restriction and exercise, are necessary to treat MetS. Initial antihypertensive therapy should consist \\ of an angiotensin-converting enzyme inhibitor or angiotensin receptor blocker. An improved understanding of the mechanism \\ responsible for the association between MetS and renal damage should be helpful in determining the treatment regimens directed \\ at cardiovascular and renal protection.
}

\section{Introduction}

Chronic kidney disease (CKD) has a major impact on the quality of life of patients, health services, and society. CKD is now also widely accepted as a risk factor for cardiovascular disease (CVD) and mortality [1-3], and recent reports, including those of observations in Japan, support this notion [4-6]. The Kidney Early Evaluation Program (KEEP) screened 6071 eligible persons for CKD and reported that $16 \%$ had a reduced estimated glomerular filtration rate (eGFR) and that $44 \%$ were obese [7]. A systematic review of 39 studies that included a total of more than a million patients revealed an increased relative risk of all-cause mortality in non-dialysis-dependent CKD patients, and the absolute risk of death appeared to increase exponentially as renal function diminished [8]. Thus, CKD is common among persons who have experienced a stroke and among patients with CVD, diabetes mellitus, and other medical conditions.

In both the Western world [9] and Japan [10], there has been an increase in the prevalence of CKD that has paralleled the increase in prevalence of obesity in recent years. The
World Health Organization (WHO) defines normal body weight on the basis of body mass index (BMI) as a BMI of 18.5-24.9, overweight as a BMI ranging from 25 to 29.9, and obesity as a BMI of 30 or more [11]. Obesity was demonstrated to be a predictor of the development of CKD in two large studies of 5897 patients and 11,104 patients, respectively $[12,13]$. Analysis of data from the Second National Health and Nutrition Examination Survey (NHANES II) in the United States identified an increased risk of CKD in persons who were morbidly obese [14].

BMI was found to be associated with an increased risk of developing end-stage renal disease (ESRD) in men in a Japanese cohort [15], and a similar positive association between CKD and obesity was demonstrated among men in a population-based study in Singapore [16]. Obesity has not only been suggested to cause renal disease, but it appears to accelerate its progression. A retrospective cohort study of 320,252 healthcare-insured participants in northern California who were followed for 15-35 years revealed that the rate of ESRD increased in a stepwise manner as BMI rose [17]. In that study, the age-, sex-, and race-adjusted rates of ESRD increased from 10 per 100,000 person-years 
among those with normal weight (BMI, 18.5 to 24.9) to 108 per 100,000 among whose BMI was greater than 40 . High BMI is likely to be a risk factor for the progression of CKD. Metabolic syndrome (MetS) is a clinical syndrome that consists of visceral obesity, dyslipidemia, hypertension, and impaired insulin sensitivity.

\section{Epidemiology of MetS and CKD}

The relationship between MetS and CKD has recently been examined. Ninomiya et al. performed a slope analysis of the association between the GFR slope and MetS by using a multiple regression model [18]. The results showed that the multivariate-adjusted mean value for the GFR slope decreased significantly in subjects with 4 or more MetS components in comparison with those who had 1 or no components, and the mean of the GFR slope was also significantly lower in subjects with $3 \mathrm{MetS}$ components in the 60 year and over age group. Chen et al. investigated the risk of developing CKD, defined by a Modification of Diet in Renal Disease study (MDRD)-eGFR of less than $60 \mathrm{~mL} / \mathrm{min}$ per $1.73 \mathrm{~m}^{2}$, in a cohort of the NHANES III study that included $>7800$ participants who had normal renal function at baseline and were followed for $>21$ years [19]. The results showed that the multivariate-adjusted odds ratio (OR) for CKD of the participants with MetS was 2.6 in relation to participants without MetS, and the OR increased from 1.89 to 5.85 as the number of components of MetS that were present increased. Importantly, the relationship persisted after exclusion of diabetes. They also found a 2fold increase in the risk for microalbuminuria that correlated with the number of components of MetS. Palaniappan et al. demonstrated a higher rate of microalbuminuria in men and women with MetS than in healthy controls [20]. The cutoff point of the urinary albumin-to-creatinine ratio varied in subjects with various CVD risk profiles, and even lowgrade albuminuria below the conventional cutoff point for microalbuminuria was associated with increased prevalence of CKD [21]. Kurella et al. performed a longitudinal cohort study and found a higher rate of CKD in MetS even after adjustment for subsequent development of diabetes and hypertension, suggesting that MetS is independently associated with an increased risk for incident CKD in nondiabetic adults [22]. These findings suggest that the onset of renal dysfunction may occur long before the appearance of hypertension or diabetes in patients with MetS.

\section{Possible Role of MetS in the Development of CKD}

In a population of nondiabetic American Indians with a high prevalence of MetS (38\%), MetS was found to be associated with an increased risk of incident CKD, but no adjustment for hypertension status was made in that study [23]. The relationship between MetS and incident CKD was stronger than among members of the population who developed diabetes during the followup period, suggesting that the development of diabetes was a likely mechanism of the increased risk of CKD associated with MetS. The authors also reported a 2.6-fold increased prevalence of CKD among adults with MetS in NHANES III [19].

Microalbuminuria has been described as the earliest manifestation of MetS-associated kidney damage and diabetic nephropathy, and it is associated with insulin resistance independent of diabetes [24]. MetS is often accompanied by increased plasma renin activity, angiotensinogen, angiotensin-converting enzyme activity, and angiotensin II (renin-angiotensin-aldosterone system) and with renal sympathetic activity. Hyperinsulinemia, insulin resistance, and increased plasma angiotensin II levels are potent activators of expression of transforming growth factor$\beta 1$, a fibrogenic cytokine that contributes to glomerular injury [25]. Microalbuminuria is attributable to augmented hyperfiltration, a well-recognized glomerular hemodynamic change in patients with MetS [26-29].

The mechanisms by which MetS causes and exacerbates CKD remain a matter of speculation (Figure 1). The hallmark of MetS is insulin resistance. Inflammatory mediators, including tumor necrosis factor (TNF)- $\alpha$, have been shown to mediate insulin resistance [30]. Adipokines, including TNF- $\alpha$, IL- 6 , and resistin, are cytokines secreted by adipose tissue, and their plasma concentrations are elevated in patients with MetS, whereas their plasma adiponectin levels are reduced. These findings may contribute to insulin resistance, and insulin resistance promotes chronic inflammation. Several studies have shown that visceral adipose tissue is a major source of adipokine secretion in MetS [31].

Adiponectin has been shown to be an adipokine that has cardiorenal protective properties [32, 33]. Plasma adiponectin levels are negatively correlated with visceral fat mass, body weight, blood pressure, insulin resistance, inflammatory markers of MetS, and high triglyceride and LDL cholesterol levels, and they are positively correlated with HDL cholesterol levels and weight loss [34]. Hypoadiponectinemia is associated with vascular dysfunction and cardiovascular events in MetS patients who do not have CKD [35]. Thus, adiponectin may be important in preventing some of the deleterious effects that the chronic inflammatory state exerts on various organs, including the kidney. Becker et al. found that low adiponectin levels in patients with mild or moderate renal dysfunction were correlated with cardiovascular events [36], whereas Menon et al. reported finding that all-cause mortality and cardiovascular mortality were paradoxically higher in patients with stage 3 or $4 \mathrm{CKD}$ who had high adiponectin levels [37], suggesting that plasma adiponectin levels are influenced by renal function. Whether adiponectin is renoprotective or cardioprotective in CKD patients with MetS is still unknown.

Activation of the renin-angiotensin-aldosterone system is common in patients with MetS despite sodium retention and a clearly increased extracellular fluid volume [38, 39]. Several mechanisms to explain its activation have been postulated: (a) hemodynamic alterations, including interference with renal blood flow [40]; (b) sympathetic stimulation, which is related to hyperleptinemia, and possibly to hyperinsulinemia and insulin resistance [41]; (c) synthesis of several proteins in the renin-angiotensin-aldosterone system by visceral fat 


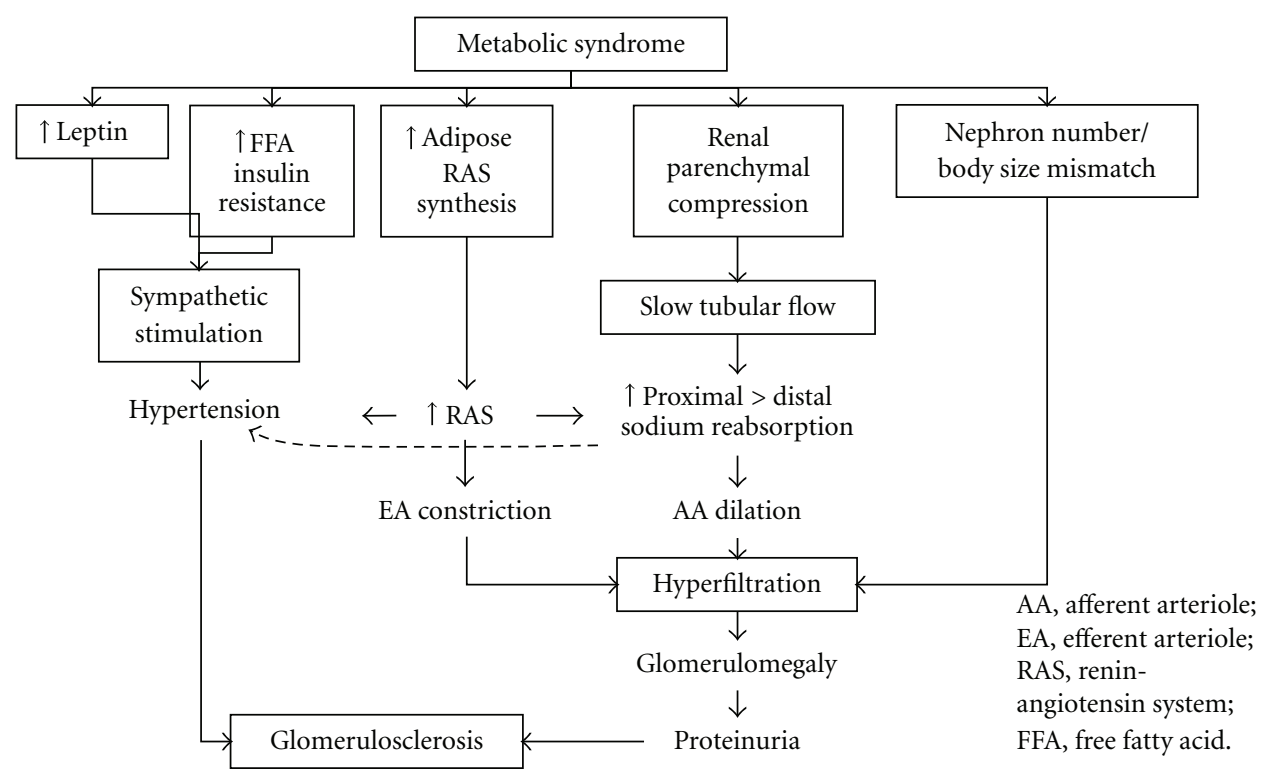

FIGURE 1: Hemodynamic consequences of obesity leading to hyperfiltration and hypertension.

tissue [42]. A review of these mechanisms has shown that hypertension, increased glomerular pressure, exacerbation of proteinuria, induction of intrarenal inflammatory cytokines and growth factors, and apoptosis are some of the deleterious effects of angiotensin II on the kidney [43]. In addition, angiotensin II may play a role in the regulation of adipokine production in adipose tissue. Since olmesartan, an angiotensin II type 1 receptor blocker, significantly reduced inflammatory cytokines and markers of oxidative stress and increased adiponectin levels in a mouse model of obesity [44], angiotensin II may adversely affect the residual renal function of patients with CKD.

With regard to potential pharmacologic therapies, it is important to note that aldosterone secretion tends to be more pronounced in obese African Americans than in obese American Whites [45]. Obesity and MetS are frequently associated with increased aldosterone levels and impaired sodium excretion [46], and this "double hit" of expanded volume and relative hyperaldosteronism may be particularly important. Several studies have reported a "mild variant of primary aldosteronism" in hypertensive African Americans and that it was even more pronounced in a subgroup with both obesity and MetS [47-49]. The assertion that antialdosterone therapy may not benefit certain races is not based on solid evidence even though there may be differences between the races in the increase in aldosterone levels.

\section{CKD as a Risk Factor for CVD}

An independent graded association has been observed between lower estimated GFR values and increased risk of death and cardiovascular events in a large communitybased population [3]. Although the initial data linking CKD and increased risk of CVD were limited and complicated by multiple confounding variables (Figure 2), CKD is now widely recognized as an independent risk factor for the development of CVD [50]. Indeed, studies of the relationship between $\mathrm{CKD}$ and CVD have generated impressive results over the last few years [51]. In many patients with CKD, the risk of death was found to be greater than the risk of progression to ESRD $[52,53]$. In recent publications that have evaluated data obtained through the National Kidney Foundation's (NKF), KEEP, and NHANES, CKD was found to be associated with significantly increased rates of myocardial infarction, stroke, and short-term mortality in comparison with the general population (Figure 3) [54]. In studies that stratified the rates of CVD and all-cause mortality according to GFR values, graded increases were seen as GFR decline even after adjusting for age and common confounders, highlighting the need for effective CVD risk reduction early in the course of CKD prior to significant loss of renal filtration function $[52,53]$.

\section{Treatment of CKD Associated with MetS}

Each of the components of MetS is capable of independently causing renal injury and increasing the risk of CKD and CVD. A number of therapeutic interventions that target individual components of MetS and associated conditions may have direct benefits on the kidney and heart. Reduction of adipose tissue mass can be achieved with preventive interventions, caloric restriction with or without physical activity. Lifestyle modifications are required to treat MetS. Weight reduction is effective in reducing proteinuria in obese patients [55, 56]. Weight loss also has a protective effect against progression of CKD to ESRD but may no longer be indicated once progression to ESRD has occurred, because renal replacement therapy has a paradoxical effect on survival [57], and a higher BMI has a beneficial effect on the survival in ESRD patients. Bariatric surgery is often performed in 


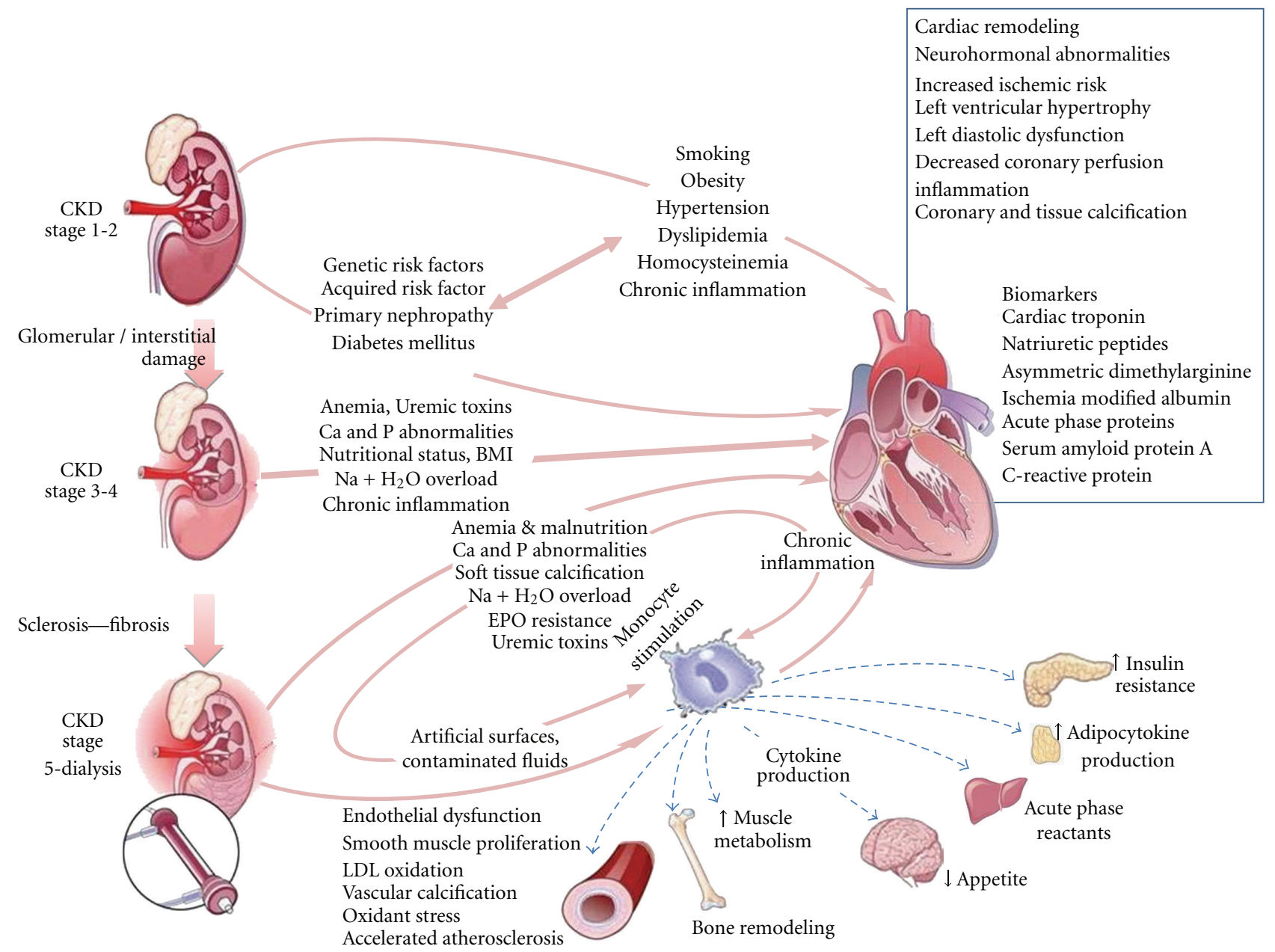

Figure 2: Complex pathogenesis of chronic kidney disease (CKD) and cardiovascular disease (CVD) [50].

cases of extreme obesity (BMI > 40). Navarro-Díaz et al. reported a remarkable improvement in glomerular hyperfiltration following recovery from renal alterations [58]. Exercise training improves various metabolic parameters, including triglyceride and HDL cholesterol levels, resting blood pressure and insulin resistance, in patients with MetS [59], and the improved metabolic profile may reduce risk of CKD and CVD.

Peroxisome proliferators-activated receptors (PPARs)$\alpha$ agonists (the fibrates) [60] and PPAR- $\gamma$ agonists (the thiazolidinediones) [61] improve insulin sensitivity, but they are not without risks in CKD patients. Blockade of the reninangiotensin system is likely to be beneficial, but treatment needs to be individualized according to the degree of renal dysfunction and whether other comorbidities associated with visceral obesity are present. The clinical merit of combination therapy of an angiotensin-converting enzyme inhibitor and an angiotensin receptor blocker remains a matter of debate. HMG-CoA reductase inhibitors seem to be effective in preventing the progression of CKD. Fried et al. found that effective treatment of dyslipidemia decreased proteinuria and retarded the progression of CKD in a meta-analysis [62]. Large randomized controlled trials to examine the effects of each of these interventions on the renal function of patients with MetS are needed before any recommendations can be made.

\section{Conclusion and Future Prospects}

MetS may be an independent risk factor for CKD and microalbuminuria in addition to being a risk factor for CVD and diabetes. Possible mechanisms by which MetS increases the risk of CKD involve inflammation, hemodynamic effects, and imbalanced adipokine secretion. Costeffective strategies to prevent CKD and ESRD that are feasible for each individual region are needed. However, few data are available on the beneficial effects of lifestyle and pharmacological interventions in CKD patients with MetS. An improved understanding of the mechanism responsible for the association between MetS and renal damage and large randomized controlled trials of therapeutic regimens designed to prevent the onset and progression of CKD should be helpful in determining which regimen is optimal.

In the next decade, there will be a significant need to conduct randomized controlled trials in order to evaluate 


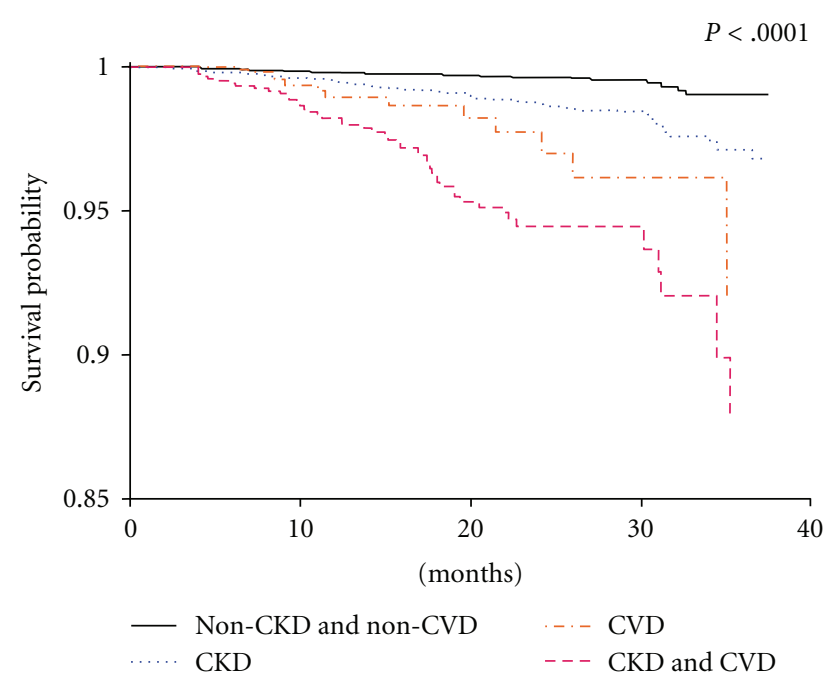

FIgURE 3: Kapla-Meier curves for all-cause mortality stratified by no chronic kidney disease (CKD)/no cardiovascular disease (CVD), prevalent $\mathrm{CKD}, \mathrm{CVD}$, and CVD + CKD from the KEEP Program [54].

the impact of the various proposed therapeutic approaches to MetS. One of the main challenges of such approaches is that the ideal outcomes of interest of such trials need to be carefully selected. The overall goal of these approaches to MetS care is to improve the quality of life. In light of this goal, it will be important to monitor multiple relevant outcomes, such as the incidence and management of CKD and CVD, together with the well-known complications of MetS.

Insulin resistance, a key mechanism of MetS, is considered the hallmark of MetS and is believed to be the underlying reason for the associated systemic metabolic derangements of hypertension and dyslipidemia, which are considered fundamental pathogenetic factors in arteriosclerosis and may contribute directly to renal injury by impairing normal hemodynamic processes through multiple mechanisms [63]. The guidelines of the American Heart Association recommend lifestyle modifications including weight reduction, dietary changes, and physical activity, as first-line therapy for patients with MetS [64].

Initial antihypertensive therapy should consist of an angiotensin-converting enzyme inhibitor or angiotensin receptor blocker, unless there are contraindications or concomitant diseases with compelling indications for other drugs. Appropriate second-line antihypertensive drugs include a calcium channel blocker or a diuretic. Most patients with MetS will need more than one antihypertensive drug to achieve the target blood pressure values. Combination therapy for multiple cardiovascular risk factors is critical to the successful management of CKD patients with MetS.

\section{References}

[1] M. J. Sarnak, A. S. Levey, A. C. Schoolwerth et al., "Kidney disease as a risk factor for development of cardiovascular disease: a statement from the American Heart Association Councils on Kidney in cardiovascular disease, high blood pressure research, clinical cardiology, and epidemiology and prevention," Circulation, vol. 108, no. 17, pp. 2154-2169, 2003.

[2] L. F. Fried, R. Katz, M. J. Sarnak et al., "Kidney function as a predictor of noncardiovascular mortality," Journal of the American Society of Nephrology, vol. 16, no. 12, pp. 3728-3735, 2005.

[3] A. S. Go, G. M. Chertow, D. Fan, C. E. McCulloch, and C.-Y. Hsu, "Chronic kidney disease and the risks of death, cardiovascular events, and hospitalization," New England Journal of Medicine, vol. 351, no. 13, pp. 1296-1370, 2004.

[4] N. S. Anavekar, J. J. V. McMurray, E. J. Velazquez et al., "Relation between renal dysfunction and cardiovascular outcomes after myocardial infarction," New England Journal of Medicine, vol. 351, no. 13, pp. 1285-1295, 2004.

[5] T. Ninomiya, Y. Kiyohara, M. Kubo et al., "Chronic kidney disease and cardiovascular disease in a general Japanese population: the Hisayama Study," Kidney International, vol. 68, no. 1, pp. 228-236, 2005.

[6] F. Irie, H. Iso, T. Sairenchi et al., "The relationships of proteinuria, serum creatinine, glomerular filtration rate with cardiovascular disease mortality in Japanese general population," Kidney International, vol. 69, no. 7, pp. 1264-1271, 2006.

[7] W. W. Brown, R. M. Peters, S. E. Ohmit et al., "Early detection of kidney disease in community settings: the Kidney Early Evaluation Program (KEEP)," American Journal of Kidney Diseases, vol. 42, no. 1, pp. 22-35, 2003.

[8] M. Tonelli, N. Wiebe, B. Culleton et al., "Chronic kidney disease and mortality risk: a systematic review," Journal of the American Society of Nephrology, vol. 17, no. 7, pp. 2034-2047, 2006.

[9] K. M. Flegal, M. D. Carroll, C. L. Ogden, and C. L. Johnson, "Prevalence and trends in obesity among US adults, 19992000," Journal of the American Medical Association, vol. 288, no. 14, pp. 1723-1727, 2002.

[10] K. Iseki, Y. Ikemiya, and K. Fukiyama, "Predictors of endstage renal disease and body mass index in a screened cohort," Kidney International, vol. 51, no. 63, pp. S169-S170, 1997.

[11] World Health Organization, Obesity: Preventing and Managing the Global Epidemic: Report of a WHO Consultation on Obesity, World Health Organization, Geneva, Switzerland, 1998.

[12] R. P. Gelber, T. Kurth, A. T. Kausz et al., "Association between body mass index and CKD in apparently healthy men," American Journal of Kidney Diseases, vol. 46, no. 5, pp. 871$880,2005$.

[13] H. Kramer, A. Luke, A. Bidani, G. Cao, R. Cooper, and D. McGee, "Obesity and prevalent and incident CKD: the Hypertension Detection and Follow-Up Program," American Journal of Kidney Diseases, vol. 46, no. 4, pp. 587-594, 2005.

[14] B. Stengel, M. E. Tarver-Carr, N. R. Powe, M. S. Eberhardt, and F. L. Brancati, "Lifestyle factors, obesity and the risk of chronic kidney disease," Epidemiology, vol. 14, no. 4, pp. 479487, 2003.

[15] K. Iseki, Y. Ikemiya, K. Kinjo, T. Inoue, C. Iseki, and S. Takishita, "Body mass index and the risk of development of end-stage renal disease in a screened cohort," Kidney International, vol. 65, no. 5, pp. 1870-1876, 2004.

[16] A. Shankar, C. Leng, K. S. Chia et al., "Association between body mass index and chronic kidney disease in men and women: population-based study of Malay adults in Singapore," Nephrology Dialysis Transplantation, vol. 23, no. 6, pp. 1910-1918, 2008.

[17] C.-Y. Hsu, C. E. McCulloch, C. Iribarren, J. Darbinian, and A. S. Go, "Body mass index and risk for end-stage renal disease," Annals of Internal Medicine, vol. 144, no. 1, pp. 21-28, 2006. 
[18] T. Ninomiya, Y. Kiyohara, M. Kubo et al., "Metabolic syndrome and CKD in a general Japanese population: the Hisayama Study," American Journal of Kidney Diseases, vol. 48, no. 3, pp. 383-391, 2006.

[19] J. Chen, P. Muntner, L. L. Hamm et al., "The metabolic syndrome and the risk for chronic kidney disease among nondiabetic adults," Annals of Internal Medicine, vol. 140, pp. 167-174, 2004.

[20] L. Palaniappan, M. Carnethon, and S. P. Fortmann, "Association between microalbuminuria and the metabolic syndrome: NHANES III," American Journal of Hypertension, vol. 16, no. 11, pp. 952-958, 2003.

[21] N. J. Heo, J. M. Ahn, T. W. Lee et al., "Very low-grade albuminuria reflects susceptibility to chronic kidney disease in combination with cardiovascular risk factors," Hypertension Research, vol. 33, no. 6, pp. 573-578, 2010.

[22] M. Kurella, J. C. Lo, and G. M. Chertow, "Metabolic syndrome and the risk for chronic kidney disease among nondiabetic adults," Journal of the American Society of Nephrology, vol. 16, no. 7, pp. 2134-2140, 2005.

[23] J. Lucove, S. Vupputuri, G. Heiss, K. North, and M. Russell, "Metabolic syndrome and the development of CKD in American Indians: the Strong Heart Study," American Journal of Kidney Diseases, vol. 51, no. 1, pp. 21-28, 2008.

[24] J. T. Lane, "Microalbuminuria as a marker of cardiovascular and renal risk in type 2 diabetes mellitus: a temporal perspective," American Journal of Physiology, vol. 286, no. 3, pp. F442-F450, 2004.

[25] J. E. Hall, “The kidney, hypertension, and obesity," Hypertension, vol. 41, no. 3, pp. 625-633, 2003.

[26] A. Chagnac, T. Weinstein, A. Korzets, E. Ramadan, J. Hirsch, and U. Gafter, "Glomerular hemodynamics in severe obesity," American Journal of Physiology, vol. 278, no. 5, pp. F817-F822, 2000.

[27] J. R. Henegar, S. A. Bigler, L. K. Henegar, S. C. Tyagi, and J. E. Hall, "Functional and structural changes in the kidney in the early stages of obesity," Journal of the American Society of Nephrology, vol. 12, no. 6, pp. 1211-1217, 2001.

[28] H.-M. Chen, S.-J. Li, H.-P. Chen, Q.-W. Wang, L.-S. Li, and Z.-H. Liu, "Obesity-related glomerulopathy in China: a case series of 90 patients," American Journal of Kidney Diseases, vol. 52, no. 1, pp. 58-65, 2008.

[29] G. S. Hotamisligil, N. S. Shargill, and B. M. Spiegelman, "Adipose expression of tumor necrosis factor- $\alpha$ : direct role in obesity-linked insulin resistance," Science, vol. 259, no. 5091, pp. 87-91, 1993.

[30] P. Dandona, A. Aljada, A. Chaudhuri, P. Mohanty, and R. Garg, "Metabolic syndrome: a comprehensive perspective based on interactions between obesity, diabetes, and inflammation," Circulation, vol. 111, no. 11, pp. 1448-1454, 2005.

[31] H. Xu, G. T. Barnes, Q. Yang et al., "Chronic inflammation in fat plays a crucial role in the development of obesity-related insulin resistance," Journal of Clinical Investigation, vol. 112, no. 12, pp. 1821-1830, 2003.

[32] J. J. Díez and P. Iglesias, "The role of the novel adipocytederived hormone adiponectin in human disease," European Journal of Endocrinology, vol. 148, no. 3, pp. 293-300, 2003.

[33] E. E. Kershaw and J. S. Flier, "Adipose tissue as an endocrine organ," Journal of Clinical Endocrinology and Metabolism, vol. 89, no. 6, pp. 2548-2556, 2004.

[34] M. Kumada, S. Kihara, S. Sumitsuji et al., "Association of hypoadiponectinemia with coronary artery disease in men," Arteriosclerosis, Thrombosis, and Vascular Biology, vol. 23, no. 1, pp. 85-89, 2003.
[35] J.-M. Fernández-Real, A. Castro, G. Vázquez et al., "Adiponectin is associated with vascular function independent of insulin sensitivity," Diabetes Care, vol. 27, no. 3, pp. 739745, 2004.

[36] B. Becker, F. Kronenberg, J. T. Kielstein et al., "Renal insulin resistance syndrome, adiponectin and cardiovascular events in patients with kidney disease: the mild and moderate kidney disease study," Journal of the American Society of Nephrology, vol. 16, no. 4, pp. 1091-1098, 2005.

[37] V. Menon, L. Li, X. Wang et al., "Adiponectin and mortality in patients with chronic kidney disease," Journal of the American Society of Nephrology, vol. 17, no. 9, pp. 2599-2606, 2006.

[38] M. L. Tuck, J. Sowers, L. Dornfeld, G. Kledzik, and M. Maxwell, "The effect of weight reduction on blood pressure, plasma rennin activity, and plasma aldosterone levels in obese patients," The New England Journal of Medicine, vol. 304, pp. 930-933, 1981.

[39] S. Engeli, J. Böhnke, K. Gorzelniak et al., "Weight loss and the renin-angiotensin-aldosterone system," Hypertension, vol. 45, no. 3, pp. 356-362, 2005.

[40] J. E. Hall, J. R. Henegar, T. M. Dwyer et al., "Is obesity a major cause of chronic kidney disease?" Advances in Renal Replacement Therapy, vol. 11, no. 1, pp. 41-54, 2004.

[41] J.-P. Montani, V. Antic, Z. Yang, and A. Dulloo, "Pathways from obesity to hypertension: from the perspective of a vicious triangle," International Journal of Obesity and Related Metabolic Disorders, vol. 26, supplement 2, pp. S28-S38, 2002.

[42] S. Engeli, P. Schling, K. Gorzelniak et al., "The adipose-tissue renin-angiotensin-aldosterone system: role in the metabolic syndrome?" International Journal of Biochemistry and Cell Biology, vol. 35, no. 6, pp. 807-825, 2003.

[43] C. Rüster and G. Wolf, "Renin-angiotensin-aldosterone system and progression of renal disease," Journal of the American Society of Nephrology, vol. 17, no. 11, pp. 2985-2991, 2006.

[44] A. Kurata, H. Nishizawa, S. Kihara et al., "Blockade of angiotensin II type-1 receptor reduces oxidative stress in adipose tissue and ameliorates adipocytokine dysregulation," Kidney International, vol. 70, no. 10, pp. 1717-1724, 2006.

[45] A. S. Bomback and P. J. Klemmer, "Interaction of aldosterone and extracellular volume in the pathogenesis of obesityassociated kidney disease: a narrative review," American Journal of Nephrology, vol. 30, no. 2, pp. 140-146, 2009.

[46] J. R. Sowers, A. Whaley-Connell, and M. Epstein, "Narrative review: the emerging clinical implications of the role of aldosterone in the metabolic syndrome and resistant hypertension," Annals of Internal Medicine, vol. 150, no. 11, pp. 776-783, 2009.

[47] C. E. Grim, A. W. Cowley Jr., P. Hamet et al., "Hyperaldosteronism and hypertension ethnic differences," Hypertension, vol. 45, no. 4, pp. 766-772, 2005.

[48] S. Kidambi, J. M. Kotchen, C. E. Grim et al., "Association of adrenal steroids with hypertension and the metabolic syndrome in blacks," Hypertension, vol. 49, no. 3, pp. 704-711, 2007.

[49] T. A. Kotchen, J. M. Kotchen, C. E. Grim, S. Krishnaswami, and S. Kidambi, "Aldosterone and alterations of hypertensionrelated vascular function in African Americans," American Journal of Hypertension, vol. 22, no. 3, pp. 319-324, 2009.

[50] P. A. McCullough and T. A. Verrill, "Cardiorenal interaction: appropriate treatment of cardiovascular risk factors to improve outcomes in chronic kidney disease," Postgraduate Medicine, vol. 122, no. 2, pp. 25-34, 2010. 
[51] National Kidney Foundation, "K/DOQI clinical practice guidelines for chronic kidney disease: evaluation, classification, and stratification," American Journal of Kidney Diseases, vol. 39, no. 2, supplement 1, pp. S1-S266, 2002.

[52] P. A. McCullough, "Cardiovascular disease in chronic kidney disease from a cardiologist's perspective," Current Opinion in Nephrology and Hypertension, vol. 13, no. 6, pp. 591-600, 2004.

[53] A. I. Adler, R. J. Stevens, S. E. Manley, R. W. Bilous, C. A. Cull, and R. R. Holman, "Development and progression of nephropathy in type 2 diabetes: the United Kingdom Prospective Diabetes Study (UKPDS 64)," Kidney International, vol. 63, no. 1, pp. 225-232, 2003.

[54] P. A. McCullough, C. T. Jurkovitz, P. E. Pergola et al., "Independent components of chronic kidney disease as a cardiovascular risk state: results from the Kidney Early Evaluation Program (KEEP)," Archives of Internal Medicine, vol. 167, no. 11, pp. 1122-1129, 2007.

[55] E. Morales, M. A. Valero, M. León, E. Hernández, and M. Praga, "Beneficial effects of weight loss in overweight patients with chronic proteinuric nephropathies," American Journal of Kidney Diseases, vol. 41, no. 2, pp. 319-327, 2003.

[56] M. Praga and E. Morales, "Weight loss and proteinuria," Contributions to Nephrology, vol. 151, pp. 221-229, 2006.

[57] K. Kalantar-Zadeh, G. Block, M. H. Humphreys, and J. D. Kopple, "Reverse epidemiology of cardiovascular risk factors in maintenance dialysis patients," Kidney International, vol. 63, no. 3, pp. 793-808, 2003.

[58] M. Navarro-Díaz, A. Serra, R. Romero et al., "Effect of drastic weight loss after bariatric surgery on renal parameters in extremely obese patients: long-term follow-up," Journal of the American Society of Nephrology, vol. 17, no. 3, pp. S213-S217, 2006.

[59] A. E. Tjønna, S. J. Lee, $\varnothing$. Rognmo et al., "Aerobic interval training versus continuous moderate exercise as a treatment for the metabolic syndrome: a pilot study," Circulation, vol. 118, no. 4, pp. 346-354, 2008.

[60] V. R. Panz, J. R. Wing, F. J. Raal, M.-A. Kedda, and B. I. Joffe, "Improved glucose tolerance after effective lipidlowering therapy with bezafibrate in a patient with lipoatrophic diabetes mellitus: a putative role for Randle's cycle in its pathogenesis?" Clinical Endocrinology, vol. 46, no. 3, pp. 365368, 1997.

[61] S. Kumar, A. Prange, J. Schulze, S. Lettis, and A. M. Barnett, "Troglitazone, an insulin action enhancer improves glycaemic control and insulin sensitivity in elderly type 2 diabetic patients," Diabetic Medicine, vol. 15, no. 9, pp. 772-779, 1998.

[62] L. F. Fried, T. J. Orchard, and B. L. Kasiske, "Effect of lipid reduction on the progression of renal disease: a meta-analysis," Kidney International, vol. 59, no. 1, pp. 260-269, 2001.

[63] P. A. Sarafidis and L. M. Ruilope, "Insulin resistance, hyperinsulinemia, and renal injury: mechanisms and implications," American Journal of Nephrology, vol. 26, no. 3, pp. 232-244, 2006.

[64] S. M. Grundy, J. I. Cleeman, S. R. Daniels et al., "Diagnosis and management of the metabolic syndrome: an American Heart Association/National Heart, Lung, and Blood Institute scientific Statement," Circulation, vol. 112, no. 17, pp. 27352752, 2005. 


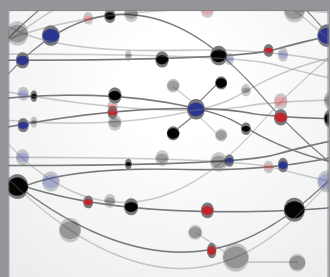

The Scientific World Journal
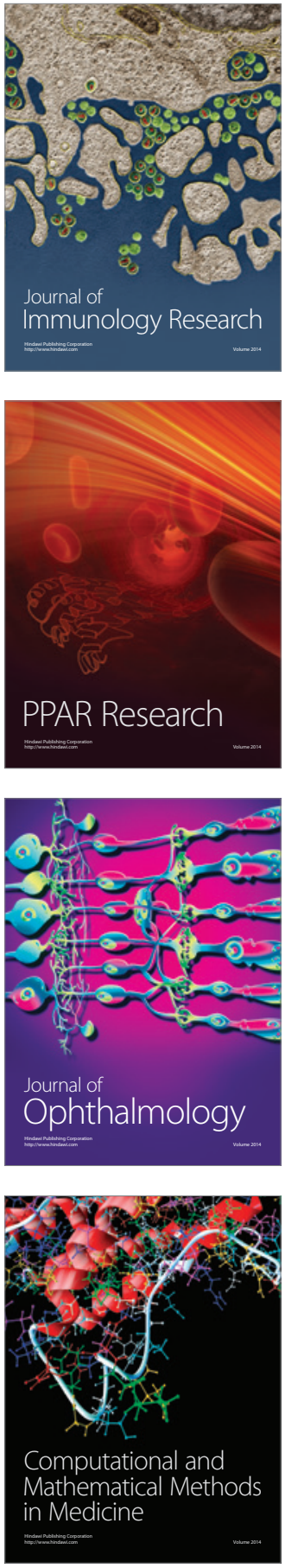

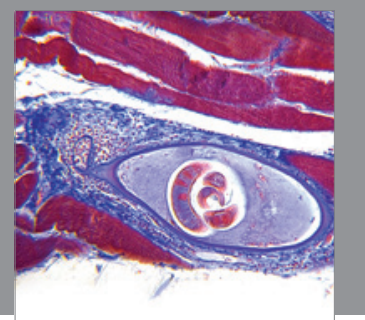

Gastroenterology

Research and Practice
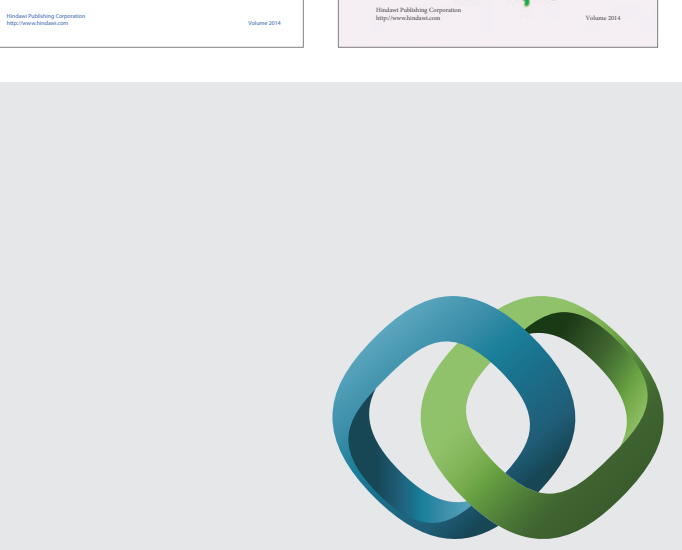

\section{Hindawi}

Submit your manuscripts at

http://www.hindawi.com
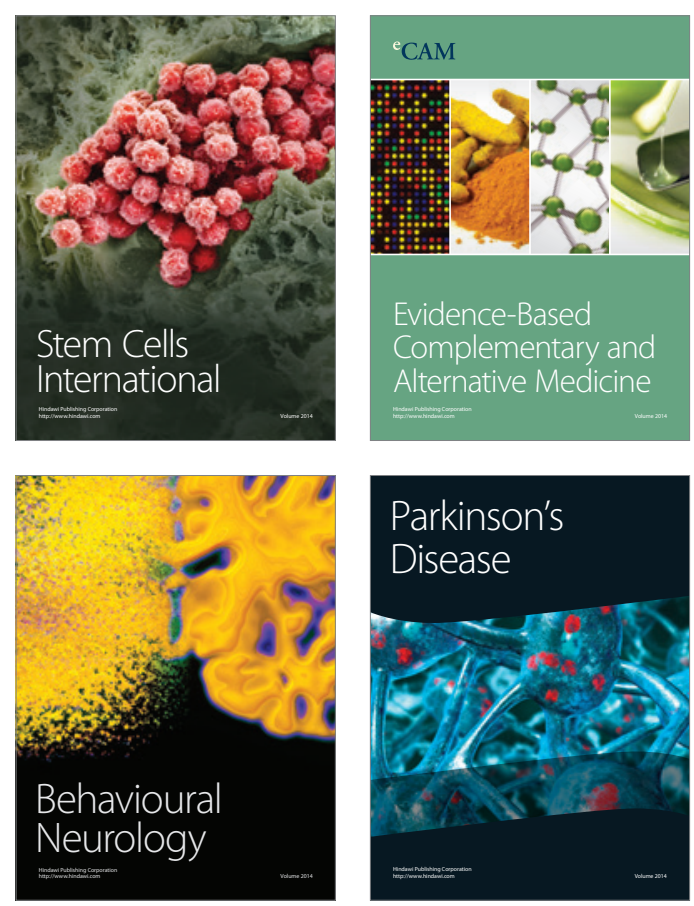

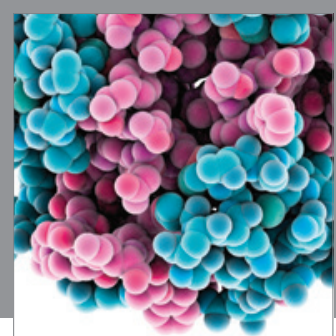

Journal of
Diabetes Research

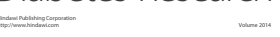

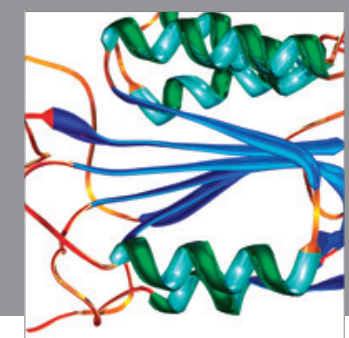

Disease Markers
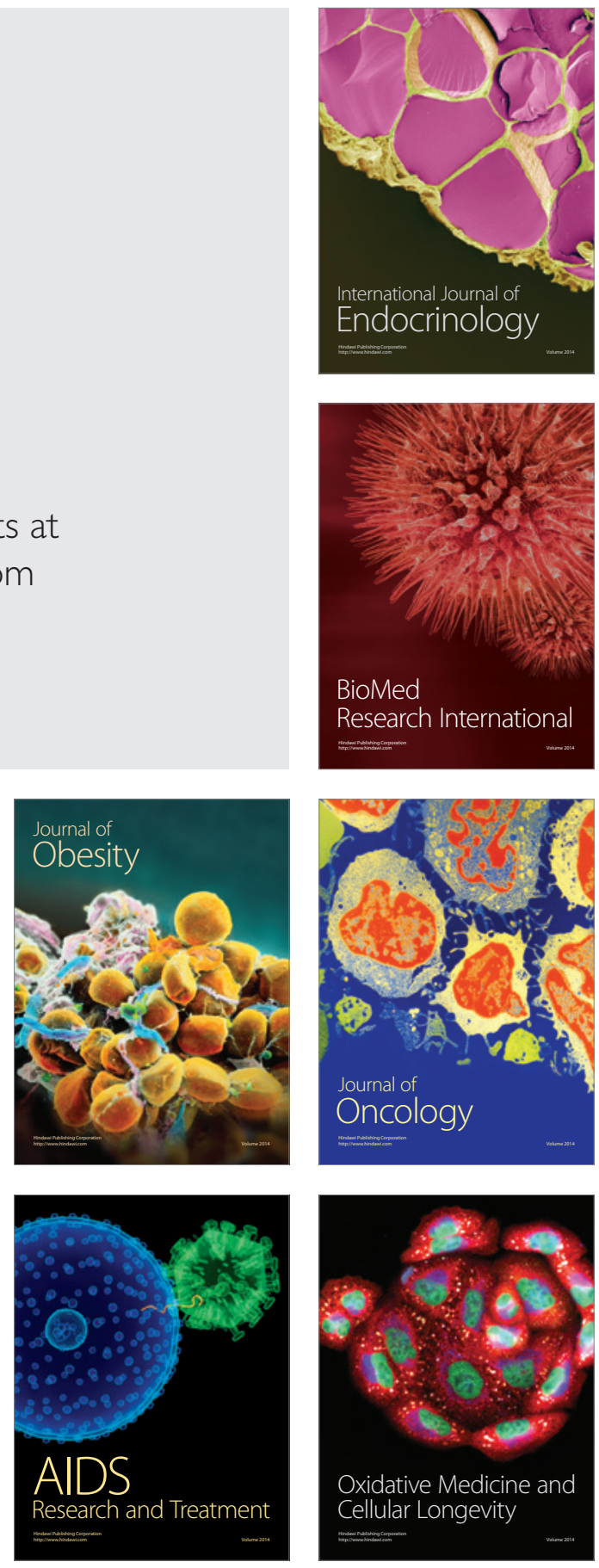